\title{
Evaluation of Anti-psoriatic Potential of the Fruit Rind of Punica granatum L.
}

\author{
Janani Jacob ${ }^{1,2^{*}}$, Gopalan $\mathrm{R}^{3}$, Lakshmanaperumalsamy P4, Ramanaiah Illuri², Damaji Bhosle², Gopala Krishna \\ Sangli ${ }^{2}$, Deepak Mundkinajeddu ${ }^{2}$
}

\section{Janani Jacob ${ }^{1,2 *}$, Gopalan $\mathrm{R}^{3}$ Lakshmanaperum- alsamy $\mathrm{P}^{4}$, Ramanaiah Illuri², Damaji Bhosle ${ }^{2}$, Gopala Krishna Sangli², Deepak $\mathbf{M}^{2}$}

${ }^{1}$ Research Scholar, Karpagam Academy of Higher Education, Coimbatore641 021, Tamil Nadu, INDIA. ${ }^{2} R$ \& D Centre, Natural Remedies Pvt. Ltd. Bangalore-560 100, Karnataka, INDIA.

${ }^{3}$ Department of Botany, Karpagam Academy of Higher Education, Coimbatore-641 021, Tamil Nadu, INDIA. ${ }^{4}$ Department of Environmental Sciences, Bharathiar University, Coimbatore-641 046, Tamil Nadu, INDIA

\section{Correspondence}

Mrs. Janani Jacob

Research Officer, Natural Remedies Pvt. Ltd. 5B, Veerasandra Industrial Area, Hosur Road. Bangalore-560 100, Karnataka, INDIA.

E-mail: janani@naturalremedy.com

Phone number: +91 8951057332

History

- Submission Date: 30-09-2018;

- Review completed: 12-12-2018.

- Accepted Date: 03-01-2019

DOI : 10.5530/pj.2019.11.73

Article Available online

http://www.phcogj.com/v11/i3

Copyright

(C) 2019 Pharmacognosy Journal. This is an open-access article distributed under the terms of the Creative Commons Attribution 4.0 International license.

\begin{abstract}
Background: Pomegranate (Punica granatum L.) is universally known for its therapeutic properties due to its potential bioactive compounds. However, there is no established scientific study on antipsoriatic activity of pomegranate fruit rind. The aim of the study is to evaluate the anti-psoriatic activity of the isolated compounds and the extract from the fruit rind of $P$. granatum. In our previous study, the isolated compounds were evaluated for antioxidant potential. In continuation to the previous investigation, the present study is taken up to evaluate the extract and compounds for in vitro anti-psoriatic activity. Methods: Chromatographic techniques were employed to isolate the compounds from the aqueous acetone extract and in vitro anti-psoriatic activity was determined by thymidine phosphorylase inhibition assay. Results: From previous phytochemical investigation, three compounds were identified as Punicalagin, 2,3(S)-hexahydroxydiphenoyl-D-glucose and Punicalin. In the present study, the extract and the compounds were evaluated for anti-psoriatic activity. The results reveal that the isolated three compounds showed inhibitory activity of $89 \%$ to $95 \%$ against thymidine phosphorylase. Aqueous acetone extract also exhibited $87 \%$ inhibition. Conclusion: Punica granatum is an ideal plant for further investigation to prove its anti-psoriatic activity. Key words: Anti-psoriatic activity, Punica granatum, Thymidine phosphorylase inhibition.
\end{abstract}

\section{INTRODUCTION}

Phytochemicals or bioactive constituents derived from the medicinal plants are commonly called as secondary metabolites and are considered as the natural source to protect various illness. ${ }^{1-2}$ In folk and traditional systems of medicines, Punica granatum (Lythraceae) has been used as a food supplement or medicine for its wide spread pharmacological activities due to the presence of its array of bioactive chemical constituents with different potency. The plant has been reported for antioxidant, antiangiogenic, antiproliferative, antibacterial and hepatoprotective activities. P. granatum reported to have polyphenols and tannins which are responsible for its potent antioxidant and anti inflammatory activity. ${ }^{3-5}$ Flavonoids in plants are known for their antioxidant effects and possible use of natural antioxidant agent for control of psoriasis is of great interest since skin is a target of oxidative stress. ${ }^{6}$

Angiogenesis, the development of new blood vessels from a pre-existing vascular bed, is a vital component of the pathogenic mechanisms involved in psoriasis. ${ }^{7-8}$ Thymidine phosphorylase is an angiogenic enzyme that catalyzes the reversible phosphorylysis of thymidine into thymine and 2-deoxy-D-ribose 1-phosphate and then the 2-deoxy-D-ribose 1-phosphate undergo dephosphorylation to produce 2-deoxy-D-ribose which is important for the angiogenic activity of thy- midine phosphorylase. Thymidine phosphorylase enzyme is reported to be present in high levels in the psoriatic lesion which is likely to induce psoriasis. ${ }^{9}$ ${ }^{16}$ Psoriasis is an autosomal, chronic inflammatory dermatitis affecting $2 \%$ of world population. It is present in all racial groups and has a strong genetic component. Plants play a significant role in the discovery of new agents for the treatment of psoriasis. ${ }^{17}$ The present study was aimed to evaluate the antipsoriatic activity of aqueous acetone extract and compounds of the fruit rind of P. granatum.

\section{MATERIALS AND METHODS}

Instruments and chemicals

Shimadzu UV Spectrophotometer UV 1800. Standards (5-Nitrouracil), chemicals and other reagents utilized were of AR grade purchased from Sigma (USA), Rankem (India) and Merck (Germany).

\section{Plant material}

Fresh fruits of Punica granatum were collected from Nilgiri District, Tamil Nadu, India and authenticated by the In-house Taxonomist, Natural Remedies Pvt Ltd., Bangalore. A voucher specimen PC/PN/ TRM125 was preserved at the Agronomy Department of Natural Remedies Pvt. Ltd., Bangalore.

Cite this article: Jacob J, Gopalan R, Lakshmanaperumalsamy P, Illuri R, Bhosle D, Sangli GK. Evaluation of Anti-psoriatic Potential of the Fruit Rind of Punica granatum L. Pharmacog J. 2019;11(3):466-8. 
Jacob, et al:: Anti-psoriatic potential of the fruit rind of Punica granatum L.

Table 1: Thymidine phosphorylase inhibition activity of isolated compounds and aqueous acetone extract of Punica granatum fruit rind

\begin{tabular}{cccc}
\hline \multirow{2}{*}{ Sample name } & \multicolumn{3}{c}{ (\% inhibition) } \\
\cline { 2 - 4 } & $10 \mu \mathrm{g} / \mathrm{ml}$ & $30 \mu \mathrm{g} / \mathrm{ml}$ & $100 \mu \mathrm{g} / \mathrm{ml}$ \\
\hline Punicalagin & $79.30+0.65$ & $90.68+0.63$ & $94.61+0.39$ \\
2,3(S)-HHDP-D-glucose & $33.33+0.71$ & $74.21+0.34$ & $89.01+0.35$ \\
Punicalin & $76.99+0.35$ & $89.27+0.22$ & $94.61+0.51$ \\
Aqueous acetone extract & $35.00+0.12$ & $76.15+0.64$ & $87.23+0.54$ \\
\hline
\end{tabular}

* The values are represented as mean $\pm \mathrm{SD}(n=3)$

\section{Extraction and isolation}

One kg of fruit rind of P. granatum was air-dried and coarsely powdered, then extracted with $75 \%$ acetone/water at $60^{\circ} \mathrm{C}$ for 1 hour for three times (3L) by reflux method. The extracts were filtered and concentrated at $60^{\circ} \mathrm{C}$ under vacuum. The aqueous acetone extract $(350 \mathrm{~g})$ was chromatographed over Diaion HP-20 resin with decreasing polarity using acetone and water. The enriched fractions were repeatedly subjected on Sephadex LH-20 with water/ acetone mixtures. The repeated purification afforded Punicalagin, 2,3(S)-hexahydroxydiphenoyl-D-glucose and Punicalin which was identified by spectral data. Detailed isolation process and characterization of the isolated compounds were described in our previous study. ${ }^{18}$

\section{Anti-psoriatic activity}

\section{Thymidine phosphorylase inhibition assay}

The aqueous acetone extract and the isolated compounds were evaluated for their in vitro thymidine phosphorylase inhibition. This assay was carried out as per Krenitsky et al. ${ }^{19}$ with slight modification. Total reaction mixture comprising Potassium phosphate buffer (200Mm, pH 7.4), different concentration of test solutions (in buffer), thymidine phosphorylase enzyme $(5 \mathrm{U} / \mathrm{ml})$ and thymidine $(3 \mathrm{mM})$ were mixed and incubated at $25^{\circ} \mathrm{C}$ for $10 \mathrm{~min}$ and the absorbance was read at $290 \mathrm{~nm}$ in UV-spectrophotometer. 5-Nitrouracil was used as a standard inhibitor.

\section{Statistical analysis}

The data were analyzed by GraphPad Prism 5.0 (GraphPad Software, Inc., San Diego, CA). Each experiment was performed in triplicates. The values are expressed as mean \pm standard deviation (SD).

\section{RESULTS AND DISCUSSION}

The fruit rind of P. granatum was extracted with $75 \%$ acetone/water which was subsequently purified over Sephadex LH-20, yielded Punicalagin, 2,3(S)-hexahydroxydiphenoyl-D-glucose and Punicalin. The extract and the isolated compounds were screened against thymidine phosphorylase. The investigation was carried out with different concentrations $(10,30$ and $100 \mu \mathrm{g} / \mathrm{ml}$ ) of the test samples and the results demonstrated a dose dependent activity with increase in the concentration [Table 1]. The inhibition is expressed in percentage (\%). The compounds and extract showed a good activity against thymidine phosphorylase [Figure 1]. The plant has been reported to contain phenolic constituents which may be responsible for the anti-psoriatic activity. There is no detailed established scientific study reported earlier on antipsoriatic activity of pomegranate fruit rind.

\section{CONCLUSION}

Pomegranate is used by the traditional healers for the ethnomedicinal preparations for various ailments including Psoriasis. The present study reveals that the fruit rind of $P$. granatum has anti-psoriatic potential which has been used in the traditional system of medicine or ethno-

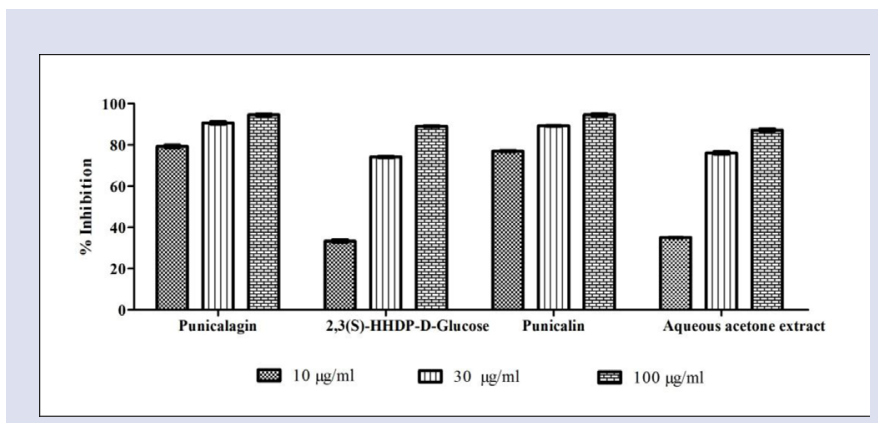

Figure 1: In vitro Thymidine phosphorylase inhibition activity of compounds and extract of fruit rind of $P$. granatum

medicine by traditional healers or tribes. It is a promising anti-psoriatic source that warrants detailed investigation for treating or controlling the psoriasis disease.

\section{ACKNOWLEDGEMENT}

The authors thank M/s. Natural Remedies Pvt. Ltd., Bangalore, India, for providing all necessary facilities to carry out the research work.

\section{CONFLICT OF INTEREST}

The authors declare no conflict of interest.

\section{ABBREVIATIONS}

HHDP: Hexahydroxydiphenoyl; UV: Ultra violet.

\section{REFERENCES}

1. Ali SS, Kasoju N, Luthra A, Singh A, Sharanabasava H, Sahu A, et al. Indian medicinal herbs as sources of antioxidants. Food Res Int. 2008;41(1):1-15.

2. Pham-Huy LA, He H, Huyc CP. Free radicals, antioxidants in disease and health. Int J Biomed Sci. 2008;4(2):89-96

3. Wang R, Ding Y, Liu R, Xiang L, Du L. Pomegranate: Constituents, bioactivities and pharmacokinetics. Fruit Veg Cereal Sci Biotechnol. 2010;4(2):77-87.

4. Ricci D, Giamperi L, Bucchini A, Fraternale D. Antioxidant activity of Punica granatum fruits. Fitoterapia. 2006:77(4):310-2.

5. Prashant D, Asha MK, Amit A. Antibacterial activity of Punica granatum. Fitoterapia. 2001;72(2):171-3.

6. Bonesi M, Loizzo MR, Provenzano E, Menichini F, Tundis R. Anti-Psoriasis Agents from Natural Plant Sources. Curr Med Chem. 2016;23(12):1250-67.

7. Ferrara N. Vascular endothelial growth factor: basic science and clinical progress. Endocr Rev. 2004;25(4):581-611.

8. Detmar M, Brown LF, Claffey KP, Yeo KT, Kocher O, Jackman RW, et al. Overexpression of vascular permeability factor/vascular endothelial growth factor and its receptors in psoriasis. J Exp Med. 1994;180(3):1141-6.

9. Focher F, Spadari S. Thymidine phosphorylase: a two-face Janus in anticancer chemotherapy. Curr Cancer Drug Targets. 2001;1(2):141-53.

10. Abbasi MA, Ahmad VU, Zubair M, Fatima N, Farooq U, Hussain S, et al. Phosphodiesterase and thymidine phosphorylase-inhibiting salirepin derivatives from Symplocos racemosa. Planta Med. 2004;70(12):1189-94.

11. Schwartz PA, Vetticatt MJ, Schramm VL. Transition state analysis of the arsenolytic depyrimidination of thymidine by human thymidine phosphorylase. Biochemistry. 2011;50(8):1412-20.

12. Friedkin M, Roberts DW. The enzymatic synthesis of nucleosides I. Thymidine phosphorylase in mammalian tissue. J Biol Chem. 1954;207(1):245-56.

13. Matsushita S, Nitanda T, Furukawa T, Sumizawa T, Tani A, Nishimoto K, et al. The effect of a thymidine phosphorylase inhibitor on angiogenesis and apoptosis in tumors. Cancer Res. 1999;59(8):1911-6.

14. Shahzad SA, Yar M, Bajda M, Jadoon B, Khan ZA, Riza NSA, et al. Synthesis and biological evaluation of novel oxadiazole derivatives: a new class of thymidine phosphorylase inhibitors as potential anti-tumor agents. Bioorg Med Chem. 2014;22(3):1008-15

15. Liekens S, Bilsen F, De Clercq E, Priego EM, Camarasa MJ, Pérez-Pérez MJ, et al. Anti-angiogenic activity of a novel multi-substrate analogue inhibitor of thymidine phosphorylase. FEBS Lett. 2002;510(1-2):83-8. 
16. Dhanabal SP, Muruganantham N, Basavaraj KH, Wadhwani A, Shamasundar NM. Antipsoriatic activity of extracts and fractions obtained from Memecylon malabaricum leaves. J Pharm Pharmacol. 2012;64(10):1501-9.

17. Haneke E. Nail psoriasis: clinical features, pathogenesis, differential diagnoses and management. Psoriasis: Targets and Therapy. 2017;7:51-63.
18. Jacob J, Lakshmanapermalsamy P, Illuri R, Bhosle D, Sangli GK, Mundkinajeddu D. In vitro Evaluation of Antioxidant Potential of Isolated Compounds and Various Extracts of Peel of Punica granatum L. Pharmacognosy Res. 2018;10(1):44-8.

19. Krenitsky TA, Bushby SRM. Stabilized thymidine phosphorylase formulation. 1-8, Burroughs Wellcome Co., Research Triangle Park, NC: United States Patent 4,178,212. 1979.

\section{GRAPHICAL ABSTRACT}

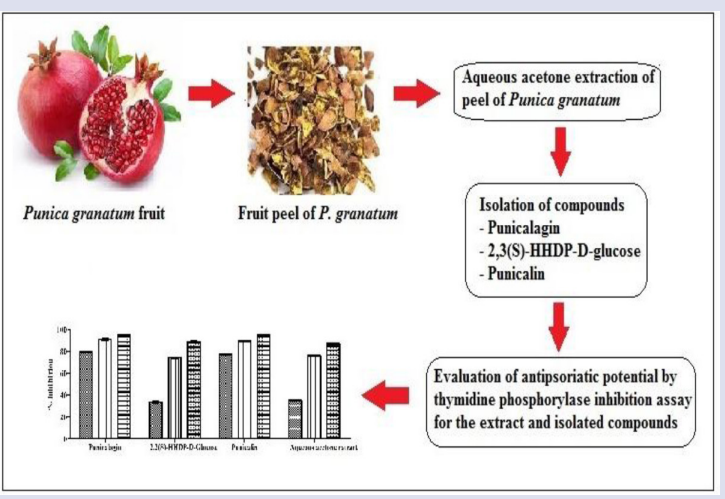

\section{SUMMARY}

- Punica granatum has anti-psoriatic potential which has been used in the traditional system of medicine.

- Punica granatum fruit rind extract were evaluated for in vitro antipsoriatic activity by thymidine phosphorylase inhibition assay.

- Aqueous acetone extract of dried fruit rind of Punica granatum and the three compounds- Punicalagin, 2,3(S)-hexahydroxydiphenoyl-D-glucose and Punicalin were evaluated for in vitro antipsoriatic activity.

- The aqueous acetone extract and the three compounds showed good inhibitory activity against thymidine phosphorylase.

Cite this article: Jacob J, Gopalan R, Lakshmanaperumalsamy P, Illuri R, Bhosle D, Sangli GK. Evaluation of Anti-psoriatic Potential of the Fruit Rind of Punica granatum L. Pharmacog J. 2019;11(3):466-8. 